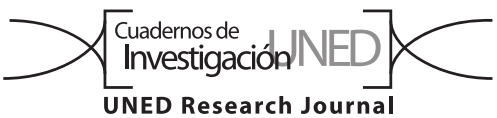

\title{
Aula en el Bosque, un programa costarricense de educación ambiental en el bosque tropical: efecto sobre estudiantes y opinión de los docentes
}

\author{
Esteban Salazar-Acuña' \& Yesenia López-García² \\ 1. Unidad Ambiental. Municipalidad de Belén, Heredia, Costa Rica; esteban2085@gmail.com \\ 2. Investigadora independiente, San José, Costa Rica; yeloga@gmail.com
}

Recibido 07-XII-2017 • Corregido 12-III-2018 • Aceptado 12-IV-2018

\begin{abstract}
Aula en el Bosque, an environmental education program for the Costa Rican tropical forest: effect on students and teacher opinions. Aula en el Bosque ("Classroom in the Forest") has over 3000 preschool and elementary school students. We applied pre and post-tests to one school per level, and to one control school. The evaluation process was in three phases: A. assessment of student comprehension and implication on the resolution of environmental issues. B. In situ development of the program in real time. C. Teachers perception of program reach. The students exposed to the program developed their own knowledge of the official curriculum, and strenghtened especially values and environmental attitudes, as confirmed by the teachers.
\end{abstract}

Keywords: Playful-didactic, constructivist education, evaluation, environmental education.
RESUMEN: Aula en el Bosque tiene más de 3000 estudiantes de preescolar y primaria. Aplicamos exámenes previos y posteriores por nivel a una escuela y a una escuela control. El proceso de evaluación se realizó en tres fases: A. evaluación de la comprensión e implicación del alumno en la resolución de problemas medioambientales. B. desarrollo in situ del programa en tiempo real. C. percepción de los profesores sobre el alcance del programa. Los estudiantes expuestos al programa desarrollaron su propio conocimiento del plan de estudios oficial y fortalecieron especialmente los valores y las actitudes ambientales, según lo confirmado por los profesores.

Palabras clave: Lúdico-didáctico, educación constructivista, evaluación, educación ambiental.
La problemática ambiental es un tema de preocupación a nivel global, ya que el impacto de las actividades humanas sobre los sistemas naturales se ha demostrado que repercutirá directamente sobre la calidad de vida de todos los habitantes del planeta (Salazar, 2015). Algunos problemas ambientales como el cambio climático, la relación entre los océanos y el clima, la contaminación del aire y del agua, requieren de una base sólida de conocimiento e investigación, pues sólo si se comprenden sus causas y consecuencias se podrá actuar correctamente (Tintoré, 2006). En este marco, la educación ambiental es fundamental, debido a que la forma en que se manejen los recursos naturales definirá la disponibilidad de los insumos necesarios para la vida a largo plazo (Espejel, Castillo \& Martínez, 2011).

La implementación de programas de educación ambiental es una estrategia mediante la cual se espera que los individuos adopten comportamientos y prácticas que permitan vivir una vida completa en armonía con la política de desarrollo sostenible (UNESCO, 2004). Para Thomson, Hoffman y Staniforth (2010) un programa de educación ambiental debe motivar y empoderar a los estudiantes a través del aprovisionamiento de habilidades específicas, que permita a los estudiantes desarrollar estrategias para una ciudadanía responsable a través de la aplicación de sus habilidades y conocimientos mientras trabajan cooperativamente en la resolución de un problema.

En Costa Rica para 1994 el Ministerio de Educación Pública (MEP) definió la ecología como el eje curricular de su política educativa y se proponen los ejes del desarrollo sostenible: el ambiental, el económico, el de sostenibilidad y el ético. Los programas de todas las materias fueron "ambientalizados", dando énfasis a valores y actitudes positivos hacia el ambiente (Guier, Rodríguez \& Zúñiga, 2000). De ahí la importancia de dirigir las 
estrategias educativas hacia la conservación del ambiente, en ese proceso es imperante que los docentes y las autoridades de los centros educativos cuenten con el acompañamiento en otros actores sociales para mejorar la realidad ambiental del país, bajo esta premisa se origina la vinculación con el Programa de Educación Ambiental Aula en el Bosque.

El Programa "Aula en el Bosque" es un proyecto de educación ambiental que nace en la Reserva Los Coyotes en Mata de Plátano en Goicoechea, pero que ha sido replicado y financiado para su aplicación por la Municipalidad de Belén, el cual se lleva a cabo desde el 2014, con una inversión anual aproximada de \$16000000,00. Inicialmente se desarrolló en la Escuela Manuel del Pilar como escuela piloto, pero a partir de 2016 se aplica en todos los niveles de primaria y preescolar de los centros educativos públicos del cantón.

La educación ambiental puede funcionar como herramienta educativa, si se considera como un proceso que va desde crear conciencia, hasta la acción capaz de promover cambios de conducta en las personas, que les oriente hacia el desarrollo sustentable y la protección del ambiente (Colón Ortiz, 2011). Basado en este principio es que se eligió como línea de acción para ejecución del programa desarrollar de forma vivencial el eje transversal de "Cultura Ambiental para el Desarrollo Sostenible" propuesto por el MEP, de manera que se generen aprendizajes constructivistas a partir de la experiencia.

Para realizar la implementación del programa, al inicio del año lectivo se realiza una reunión de la educadora ambiental con el personal docente de cada uno de los cuatro centros educativos públicos del cantón y se coordina el contenido de las visitas en conjunto, siguiendo los programas de estudio del Ministerio de Educación Pública (MEP). Los niveles de primer ciclo, segundo ciclo y aula integrada realizan tres visitas anuales y por su parte preescolar cumple con dos visitas al año.

La ejecución completa del proceso se compone de tres momentos metodológicos; primeramente se requiere de un proceso previo a la visita donde los niños adquieren la conceptualización de la temática base con su docente, durante la visita cuentan con una primera parte que consiste en actividades lúdico-didácticas y posteriormente se realiza el aprendizaje de forma vivencial dentro del espacio de bosque a partir de actividades de acercamiento al entorno para reforzar la aprehensión de los conceptos a cargo de la educadora ambiental. Posterior a la realización de cada visita, en la etapa de cierre los niños realizan las respectivas estrategias de evaluación que determinen sus docentes en el salón de clase.
La visita propiamente se divide en dos etapas, en una primera fase se recibe a los niños en las aulas ambientales, ubicadas en la biblioteca municipal y ahí se repasan los conceptos vistos en clase con sus docentes. Para la realización de esta fase se han elaborado 28 dinámicas adaptadas según temática correspondiente por nivel, las cuales propician la participación equitativa y la generación de conocimiento por parte de los estudiantes. Posteriormente, estos conocimientos son reforzados mediante una visita al parche de cobertura boscosa más extenso del Cantón denominado "El Nacimiento". En ese espacio de aproximadamente $2 \mathrm{Ha}$ los niños cuentan con herramientas de trabajo de campo como lupas, pinzas y binoculares entre otros, que les facilita el acercamiento con el recurso, para así ejemplificar los conceptos por medio de la observación in situ. En total, los estudiantes de I y II ciclo realizan tres visitas anuales al programa (una por trimestre).

Actualmente este programa cuenta con más de 3000 estudiantes participantes de preescolar y primaria, lo que implica que el programa posee un alcance cantonal. Sin embargo, pese a la gran inversión de recursos necesarios en el programa por parte de la municipalidad, no existe un proceso de evaluación continua, lo cual denota un vacío con respecto al reconocimiento de las características educativas que posee, considerando que lo que impera en la actualidad es el paradigma constructivista de la educación

Según Ávila, Calatayud, Cantón, Castillo y Zaitegui (2010) la evaluación en la educación garantiza la calidad y mejora del proceso de enseñanza. La realización de este análisis permitió establecer aspectos que requieren mejoras metodológicas en la aplicación del programa, con lo que se puede evitar que a futuro se repitan prácticas que no alcanzan los objetivos propuestos o bien, promover aquellas prácticas que están teniendo un mejor alcance sobre el estudiantado. Para este fin se abordó un proceso de evaluación con dos centros educativos de primaria del cantón de Belén.

\section{MÉTODOS}

Para la realización de la evaluación del programa Aula en el bosque, se llevó a cabo un diseño cuasi-experimental de pre-test post-test, con grupo control no equivalente, en el que fueron seleccionados dos centros educativos públicos del cantón de Belén, Costa Rica.

El primer centro educativo evaluado fue la Escuela Manuel del Pilar Zumbado González, ubicada en distrito de La Asunción de Belén. El segundo centro educativo fue la Escuela Fidel Chaves Murillo, ubicada en el distrito de 
la Ribera de Belén. Se utilizó como control al centro educativo Escuela Pedro María Badilla, ubicado en el distrito central del cantón de San Rafael de Heredia. La selección de este centro educativo como control se basó en la similitud en su entorno urbano, la facilidad de los investigadores para contar con el aval de la dirección de la escuela para evaluar a sus estudiantes y porque no existen programas formales de educación ambiental en el centro, lo que permite que sea un control comparativo óptimo.

Según Salazar (2015) estos dos centros educativos se encuentran ubicados en los centros de población de dos distritos del Cantón y ambos se caracterizan por contar con estudiantes desde preescolar hasta sexto grado. En el caso de la Escuela Manuel del Pilar la población estudiantil es de 500 estudiantes, mientras que la Escuela Fidel Chaves supera los 1000 estudiantes en el 2017.

En cada centro educativo evaluado se seleccionaron no al azar tres grupos participantes en el programa "Aula en el Bosque", correspondientes a cada nivel del primer ciclo de la educación general básica (de primer a tercer grado). En el caso de la escuela control, los grupos fueron seleccionados de forma aleatoria entre los grupos existentes al momento de la evaluación

El proceso de evaluación fue dividido en tres fases, A. la evaluación de la comprensión de los temas desarrollados en el Programa por los estudiantes y su implicación en la resolución de problemáticas ambientales, B. el desarrollo del programa en tiempo real (in situ) y C. la percepción del personal docente acerca de los alcances del programa. Esta propuesta metodológica fue replicada de igual manera en los tres grupos poblacionales seleccionados.

\section{A. Comprensión de los temas ambientales por par-} te de los estudiantes: Para la evaluación de la comprensión de los temas ambientales se tomaron como sujetos de estudio a estudiantes entre 6 y 9 años, cursando el primer ciclo en los centros educativos seleccionados. Como herramienta de muestreo se le aplicaron cuestionarios a los estudiantes, que constaron de preguntas apoyadas con imágenes en donde se debía encerrar elementos o colocarlos en el sitio adecuado según los datos ambientales consultados.

Se aplicaron dos cuestionarios, uno "pre-test", antes de la visita al programa (máximo dos días antes de la visita) y otro "post-test", realizado una semana después de la visita en donde se evaluó el grado de aprendizaje del estudiantado para un mismo tema y su percepción acerca de lo aprendido siguiendo la metodología aplicada por Hernández (2013). La aplicación de los cuestionarios se realizó directamente en cada centro educativo, sin que los estudiantes o los docentes estuvieran enterados con antelación, con el fin de evitar sesgar el resultado.

En ambos casos ("pre-test"y"post-test"), los instrumentos de evaluación aplicados a los estudiantes solicitaban acciones fundamentales como encerrar, pintar y subrayar imágenes vinculadas con los temas desarrollados en la visita. Cada cuestionario contaba con ocho imágenes, según las cuales los estudiantes debían realizar alguna de las acciones antes mencionadas. En correspondencia a la cantidad de acciones correctas, el cuestionario fue calificado en "Deficiente" (dos o menos acciones correctas), "Aceptable" (entre tres y cuatro acciones correctas), "Bueno" (entre cinco y seis acciones correctas) y "Muy Bueno" (entre siete y ocho acciones correctas).

Se realizó una prueba t (comparación de medias) mediante el programa INFOSTAT para determinar si existió diferencia significativa entre el "pre-test" y "post-test" aplicados a los grupos de estudiantes de cada nivel evaluado. En el caso del grupo control, la evaluación permitió medir el grado de aprendizaje de los temas del currículo en condiciones ajenas al programa (grupo control) y compararlas con los resultados de los estudiantes expuestos a la ejecución del programa.

B. Ejecución del programa In situ: Se utilizó una matriz de Leopold, Clarck, Hanshaw y Balsley (1971) modificada, para la evaluación de las actividades del programa in situ. La relación entre las actividades y los factores de incidencia se identifican a través de dos números que representan respectivamente a la magnitud (en una escala de $-10 a+10$ ) y la importancia (en una escala de 1 a 10). La sumatoria de las relaciones determina el impacto de la actividad sobre el factor analizado.

La matriz de evaluación consideró tres factores fundamentales los cuales corresponden a la planificación de las actividades por parte del evaluador, el cumplimiento de la metodología propuesta para cada visita y la determinación de actitudes y valores promovidos en los estudiantes durante las visitas. En total se realizaron dos evaluaciones por cada grupo poblacional seleccionado para ser estudiado.

Pese a que el método es elementalmente cualitativo, ya que la selección de la importancia es asignada por el investigador, la determinación del impacto de una actividad puede expresarse en términos numéricos. Los factores determinados para ser considerados en la matriz de evaluación son a) la planificación, b) la metodología y c) la determinación de habilidades en los estudiantes; mientras que las actividades que impactan estos factores dependerán de la visita y el nivel evaluado. En el caso de la determinación de las habilidades en los estudiantes, 
se subdividió en determinación de habilidades "duras" (habilidades cognitivas y de aprendizaje) y habilidades "blandas" (desarrollo de habilidades sociales y de resolución de problemas).

\section{Percepción de los docentes acerca del Programa} Aula en el Bosque: En el caso de los docentes, se aplicó una encuesta para determinar una valoración acerca del programa y el grado de satisfacción que muestran con el desarrollo de las actividades realizadas durante de la visita a las aulas ambientales y a la naciente. La encuesta fue del tipo Likert en escala de 5 categorías, desde un valor 1 (completamente en desacuerdo) hasta 5 (completamente de acuerdo), se empleó la escala propuesta por Hernández (2013). Las opciones planteadas a los docentes para cada variable evaluada fueron: 1) Completamente en desacuerdo, 2) Parcialmente en desacuerdo, 3) Neutro, 4) De acuerdo, 5) Completamente de acuerdo.

La encuesta fue dividida en 4 secciones de interés de evaluación: técnicas y estrategias, diseño de la clase en las aulas ambientales, diseño del recorrido de campo y satisfacción del programa, en donde se realizó una adaptación de la encuesta propuesta por Hernández (2013), según la realidad del programa basado en las particularidades socioambientales propias del cantón de Belén. Al tratarse de una valoración de los docentes que visitaron junto con sus estudiantes el programa, no se realizó un análisis por centro educativo, sino que las respuestas brindadas fueron analizadas de forma global.

\section{RESULTADOS}

Comprensión de los temas ambientales por parte de los estudiantes: Para determinar la comprensión de las temáticas ambientales abordadas en el Programa, en la Escuela Manuel del Pilar, se encuestaron 21 estudiantes de primer grado (Grupo 1-1), 24 estudiantes de segundo grado (Grupo 2-2) y 27 estudiantes de tercer grado (Grupo 3-2). Para la Escuela Fidel Chaves se aplicaron encuestas a 26 estudiantes de primer grado (Grupo 1-2), 28 estudiantes de segundo grado (Grupo 2-2) y 28 estudiantes del tercer grado (Grupo 3-3).

En total se evaluó a 154 estudiantes de las dos instituciones educativas. El centro educativo control (Escuela Pedro María Badilla) estuvo conformado por 28 estudiantes de primer grado, 24 estudiantes de segundo grado y 22 estudiantes de tercer grado para un total de 74 estudiantes (Fig. 1).

Se encontró que en la Escuela Manuel del Pilar el 74\% de los estudiantes respondieron el instrumento de pretest dentro de las categorías de "Bueno" y "Muy bueno" (arriba del 80\% de las respuestas correctas), mientras en la Escuela Fidel Chaves, el $72 \%$ de los estudiantes contestaron con más de un $80 \%$ de aciertos. En ninguno de los dos centros educativos se obtuvieron resultados "Deficientes" o "muy deficientes".

La aplicación de los post-test mostró que el 91\% de los estudiantes de la Escuela Manuel del Pilar alcanzaron las categorías de "Bueno" y "Muy bueno", mientras que el 89\% de la Escuela Fidel Chaves alcanzó las categorías más altas en el "post-test" (Fig. 2). Esto indica que los estudiantes comprendieron de una forma más clara los contenidos desarrollados durante la visita.

Los resultados demuestran que los estudiantes de primer ciclo de las escuelas de Belén seleccionadas comprendieron mejor los contenidos después de la visita al programa. Lo anterior basado en que el porcentaje de estudiantes que responden en las categorías más altas de

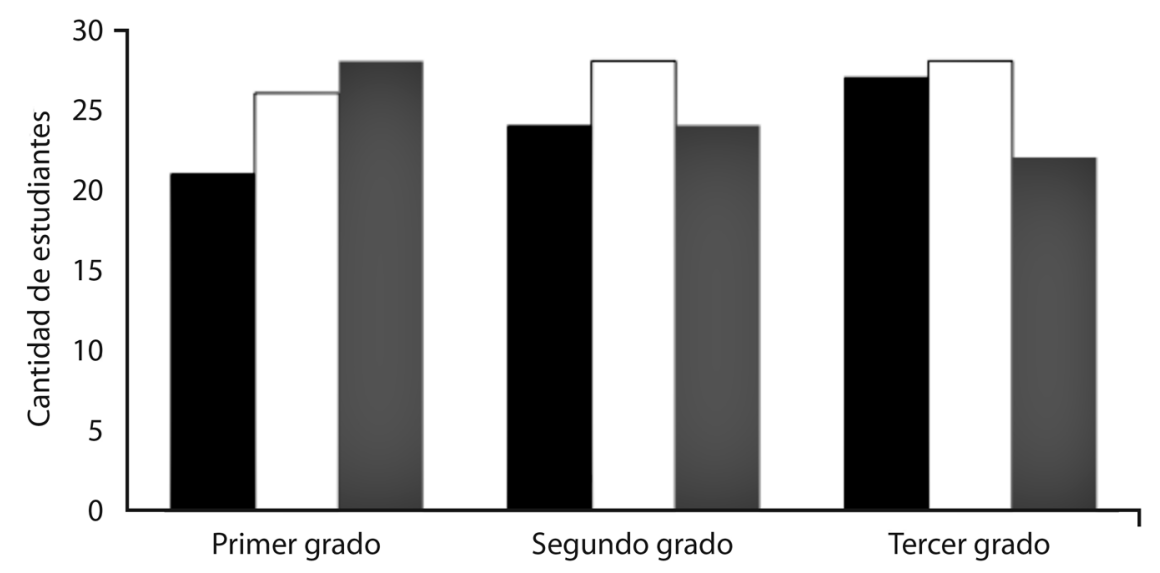

Fig. 1. Cantidad de cuestionarios aplicados por nivel en los dos centros educativos de primaria evaluados del cantón de Belén y en el Centro Educativo control. 

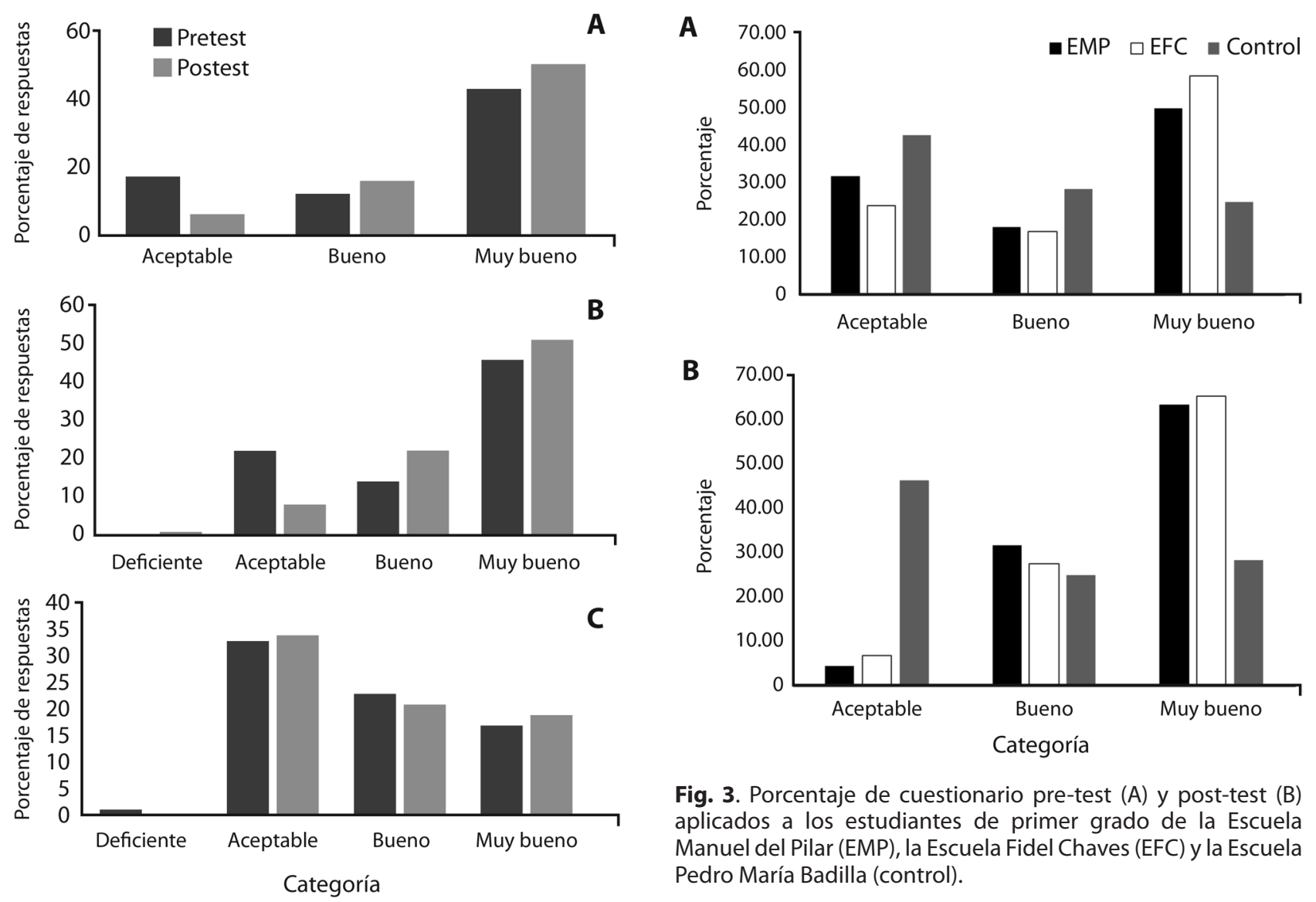

Fig. 3. Porcentaje de cuestionario pre-test (A) y post-test (B) aplicados a los estudiantes de primer grado de la Escuela Manuel del Pilar (EMP), la Escuela Fidel Chaves (EFC) y la Escuela Pedro María Badilla (control).

Fig. 2. Respuesta general en (porcentaje) a los cuestionarios pre-test y post-test de los estudiantes de la Escuela Manuel del Pilar(A), Escuela Fidel Chaves (B) y la Escuela Pedro María Badilla, centro educativo control (C).

la escala de calificación aumenta significativamente en el post-test, mientras que el grupo control no mostró cambios significativos en el tiempo $\left(x^{2}=5,55 ;\right.$ g.l. $\left.=2 ; p<, 05\right)$. Lo anterior se demuestra que existe dependencia de la visita al programa entre la cantidad respuestas en la categoría "Aceptable" $\left(x^{2}=61,74 ;\right.$ g.l. $\left.=2 ; p<, 0001\right)$, en la categoría "Bueno" $\left(x^{2}=24,08 ;\right.$ g.l. $\left.=2 ; p<, 0001\right)$ y en la categoría "Muy bueno" $\left(x^{2}=36,82 ;\right.$ g.l. $\left.=2 ; p<, 0001\right)$ entre el Pretest $y$ el Postest en las escuelas expuestas al programa (Fig. 3).

Respecto a los resultados obtenidos con los estudiantes de segundo grado, la tendencia fue similar, a la encontrada en el análisis aplicado a primer grado. Tras la aplicación del post-test el porcentaje de estudiantes que contestaron correctamente aumentó con respecto al pre-test, especialmente en la Escuela Fidel Chaves, en donde las categorías superiores aumentaron los porcentajes de respuesta (Fig. 4).

Lo anterior indica que la tendencia mostrada en el primer grado se mantiene en el segundo grado, en donde

los estudiantes pueden resolver de una mejor manera problemas. De igual forma, en el caso de los resultados de segundo grado, la tendencia fue similar, tras la aplicación del post-test, el porcentaje de estudiantes que contestaron correctamente aumentó con respecto al pre-test; especialmente en la Escuela Fidel Chaves en donde las categorías superiores aumentaron los porcentajes de respuesta (Fig. 4).

Por último, las respuestas de los estudiantes de tercer grado mostraron que existió una mejora considerable en las respuestas posterior a la visita al Programa, especialmente en la categoría de mejor desempeño ("Muy bueno"), lo cual responde a la tendencia encontrada en los niveles anteriores (Fig. 5). Respecto al grupo control se observa que sus bases teóricas son aceptables y se mantiene la misma tendencia de respuestas en el desarrollo de los ejercicios, lo cual coincide con los resultados obtenidos en los niveles anteriores y demuestra que la respuesta es similar que en el primer y segundo grado.

La aplicación de los instrumentos sobre los estudiantes mostró que los contenidos temáticos desarrollados en el programa son mejor comprendidos después de la visita de los estudiantes al programa en ambas escuelas. 

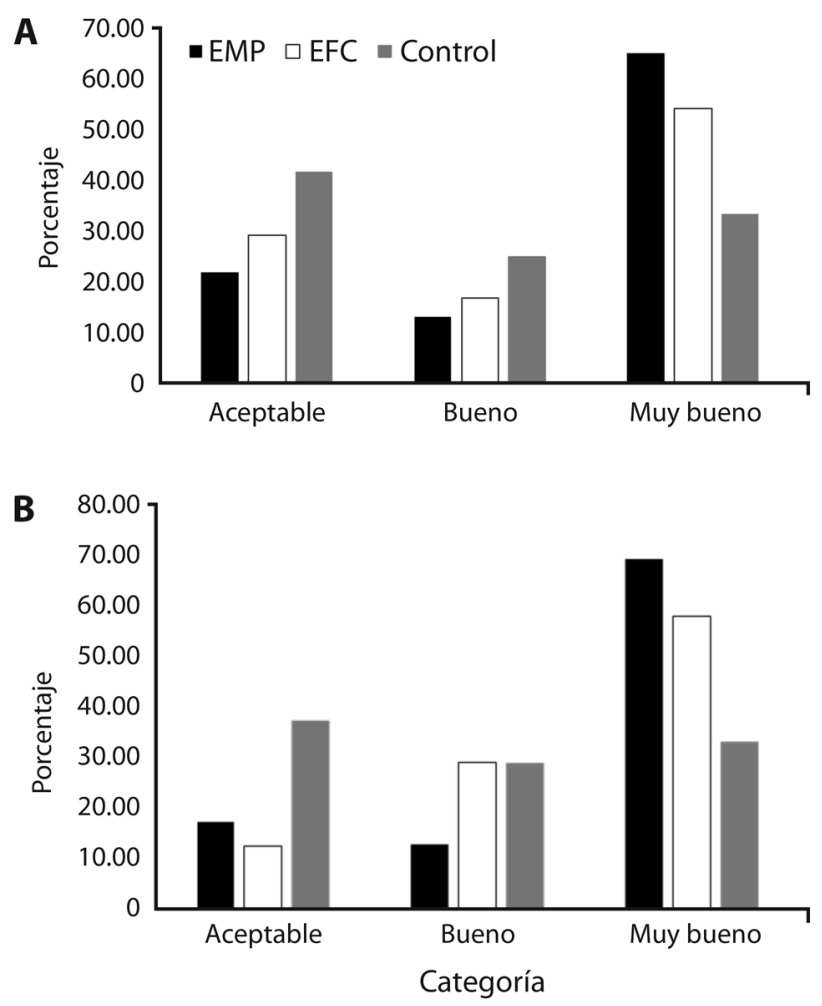

Fig. 4. Porcentaje de cuestionario pre-test (A) y post-test (B) aplicados a los estudiantes de segundo grado de la Escuela Manuel del Pilar (EMP), la Escuela Fidel Chaves (EFC) y la Escuela Pedro María Badilla (control).

Las pruebas de comparación de medias aplicadas demostraron que existió diferencias significativas en las categorías "bueno" (prueba t; $p<, 04 ; a=, 05$ ) y "muy bueno" (prueba t; $p<, 05 ; a=, 05$ ). las categorías inferiores no mostraron una diferencia significativa entre el "Pre-test" y el "Pos-test".

Ejecución del programa In situ: El abordaje de los temas relacionados al eje transversal "Cultura para el Desarrollo Sostenible" fue evaluado junto con los demás aspectos del desarrollo de las actividades presenciales
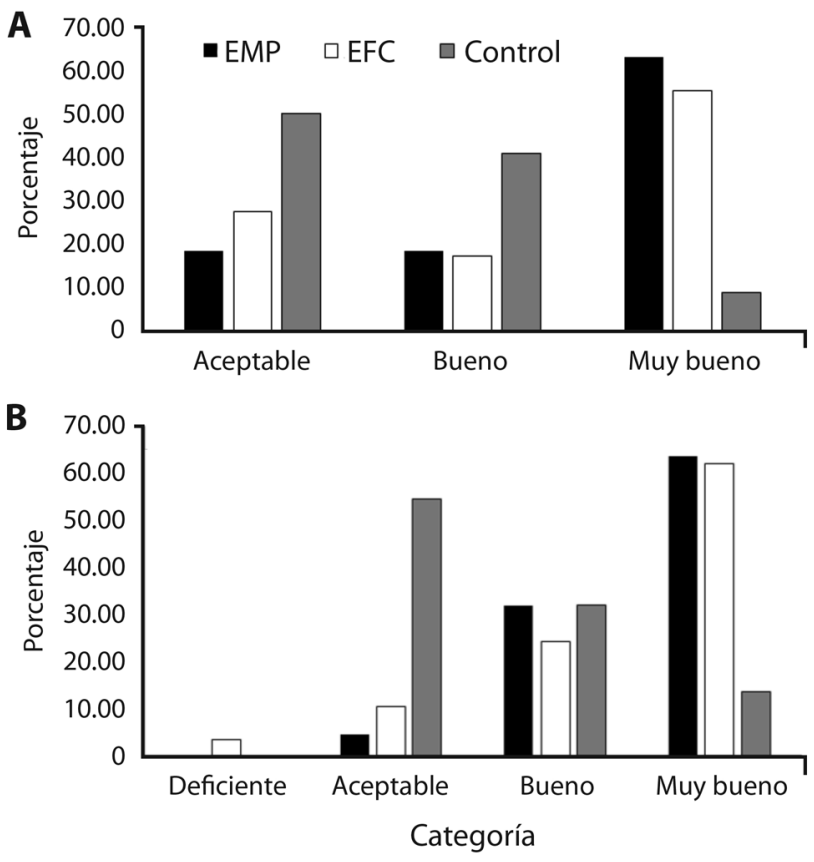

Fig. 5. Porcentaje de cuestionario pre-test (A) y post-test (B) aplicados a los estudiantes de tercer grado de la Escuela Manuel del Pilar (EMP), la Escuela Fidel Chaves (EFC) y la Escuela Pedro María Badilla (control).

del programa por medio de las matrices de evaluación. Cada matriz fue específica para cada nivel, por lo tanto, los temas desarrollados responden a la actividad programada para la visita respectiva según el nivel correspondiente, por lo tanto. la evaluación permitió identificar condiciones puntuales en primer grado, segundo grado y tercer grado respectivamente.

En general no se encontraron impactos negativos de las actividades sobre los factores evaluados en ninguna de las visitas realizadas, por lo que se puede decir que las evaluaciones de campo muestran un impacto positivo sobre el desarrollo de los temas abordados. En cada nivel evaluado, los puntajes obtenidos al aplicar la matriz fueron similares entre las diferentes evaluaciones y entre los centros educativos (Cuadro 1).

\section{CUADRO 1}

Puntajes Obtenidos en las evaluaciones de la matriz de evaluación por nivel de las visitas de los grupos de I Ciclo de las escuelas públicas de Belén al Programa Aula en el Bosque en el primer semestre del 2017.

\begin{tabular}{lcccccc} 
& \multicolumn{4}{c}{ Nivel } \\
\cline { 2 - 6 } \multicolumn{1}{c}{ Centro educativo } & \multicolumn{2}{c}{ Primer grado } & \multicolumn{2}{c}{ Segundo grado } & \multicolumn{2}{c}{ Tercer grado } \\
\cline { 2 - 7 } & $\begin{array}{c}\text { Primera } \\
\text { evaluación }\end{array}$ & $\begin{array}{c}\text { Segunda } \\
\text { evaluación }\end{array}$ & $\begin{array}{c}\text { Primera } \\
\text { evaluación }\end{array}$ & $\begin{array}{c}\text { Segunda } \\
\text { evaluación }\end{array}$ & $\begin{array}{c}\text { Primera } \\
\text { evaluación }\end{array}$ & $\begin{array}{c}\text { Segunda } \\
\text { evaluación }\end{array}$ \\
Escuela Manuel del Pilar & 4692 & 4665 & 6657 & 6555 & 3650 & 3626 \\
Escuela Fidel Chaves & 4602 & 4650 & 6645 & 6701 & 3621 & 3528 \\
Valor máximo de la evaluación & & 5000 & & & 7000 & 4000 \\
\hline
\end{tabular}


Si se comparan los resultados de los cuestionarios aplicados a los estudiantes expuestos en el apartado anterior, con lo encontrado en las evaluaciones "in situ" aplicadas en las visitas de los estudiantes al Programa, se puede suponer que el desempeño del programa en el cumplimiento de los objetivos ambientales, especialmente en lo relativo a la promoción de valores y actitudes permite que los participantes adquieran de una forma más "natural" el conocimiento teórico del currículo, al mismo tiempo que se refuerzan los valores ambientales.

En todas las evaluaciones se obtuvieron datos positivos cercanos a los valores máximos posibles alcanzables en la matriz. No obstante, el nivel que mejor evaluación mostró fue segundo grado en ambas instituciones educativas, mientras que fue el tercer grado el nivel que menor puntuación obtuvo en las evaluaciones de campo.

Los resultados encontrados en la escuela Fidel Chaves mostraron que el factor de "valores y actitudes" fue el que mejor resultado registró en las visitas, mientras que el manejo del tiempo fue el factor evaluado con menor puntaje. No obstante, los valores obtenidos no fueron significativamente bajos con respecto a los demás factores evaluados en campo (Cuadro 2 ).

De igual forma, el manejo del tiempo fue el factor que menor calificación obtuvo durante las visitas en la Escuela Manuel del Pilar Zumbado y el rango de porcentaje mayor correspondió al de fortalecimiento de actitudes y valores ambientales (Cuadro 3) La evaluación en las actividades "in situ" demuestran una buena aplicación de las visitas de campo y sus actividades, lo que indica que el programa en la Escuela Manuel del Pilar se ejecuta se forma adecuada según el planeamiento, no obstante se debe reforzar el elemento correspondiente al manejo del tiempo. Para el abordaje de estas mejoras es recomendable trabajarlo en conjunto con el personal docente de las instituciones participantes en el programa y la educadora ambiental a cargo de la ejecución.

\section{Percepción de los docentes acerca del programa}

Aula en el bosque: La encuesta muestra que la mayoría de los educadores consideran que la cantidad de visitas es insuficiente. En general, la valoración de los docentes hacia el programa alcanzó el promedio de 4,76 , en escala de 1 a 5 , lo que corresponde a un 95\% de satisfacción en los diferentes componentes del programa (Cuadro 4).

Este grado de satisfacción encontrado responde a que el programa registró un alto nivel de cumplimiento en su ejecución, por lo que los docentes afirman que se cumplen los objetivos educativos del programa, al mismo tiempo que se genera interés en los estudiantes por volver a participar.

\section{CUADRO 2}

Puntajes obtenidos por factor evaluados por la aplicación de la matriz de evaluación durante las visitas de campo del programa "Aula en el Bosque" en los estudiantes de primaria de la Fidel Chaves en el primes semestre del 2017.

\begin{tabular}{|c|c|c|c|c|c|c|c|c|}
\hline & Visitas $r$ & alizadas & Prime & grado & Segun & grado & Terce & grado \\
\hline & Factores desarrolla & dos durante la visita & 1 & 2 & 3 & 4 & 5 & 6 \\
\hline Planificación & $\begin{array}{l}\text { Planificación de los } \\
\text { contenidos }\end{array}$ & $\begin{array}{l}\text { Planificación previa } \\
\text { (hoja de planeamiento) }\end{array}$ & 485 & 478 & 679 & 688 & 376 & 369 \\
\hline & & $\begin{array}{l}\text { Aplicación de la planificación } \\
\text { durante la visita }\end{array}$ & 463 & 476 & 662 & 665 & 378 & 361 \\
\hline & Secuenciación & Manejo del tiempo & 435 & 418 & 621 & 633 & 318 & 333 \\
\hline & & $\begin{array}{l}\text { Desarrollo de los temas } \\
\text { (básicos y de profundización) }\end{array}$ & 465 & 465 & 687 & 674 & 355 & 356 \\
\hline Metodología & Estrategias & Materiales & 450 & 487 & 676 & 682 & 365 & 338 \\
\hline & metodologicas & Recursos didácticos & 461 & 458 & 670 & 677 & 344 & 340 \\
\hline & & Abordaje de los temas & 463 & 463 & 663 & 677 & 362 & 343 \\
\hline Determinación & Habilidades & Desarrollo de habilidades "duras" & 435 & 456 & 645 & 668 & 365 & 356 \\
\hline & & Desarrollo de habilidades "blandas" & 455 & 462 & 657 & 648 & 360 & 351 \\
\hline & Actitudes y valores & $\begin{array}{l}\text { Fortalecimiento de valores } \\
\text { y actitudes ambientales }\end{array}$ & 491 & 492 & 685 & 689 & 387 & 381 \\
\hline Total & & & 4602 & 4560 & 6645 & 6701 & 3612 & 3528 \\
\hline
\end{tabular}

* En amarillo se muestran las variables mejor calificadas y en gris las variables con el menor puntaje. 


\section{CUADRO 3}

Puntajes obtenidos por factor evaluados por la aplicación de la matriz de evaluación durante las visitas de campo del programa "Aula en el Bosque" en los estudiantes de primaria de la Escuela Manuel del Pilar en el primer semestre del 2017.

\begin{tabular}{|c|c|c|c|c|c|c|c|c|}
\hline \multicolumn{3}{|c|}{ Visitas realizadas } & \multicolumn{2}{|c|}{ Primer grado } & \multicolumn{2}{|c|}{ Segundo grado } & \multicolumn{2}{|c|}{ Tercer grado } \\
\hline \multicolumn{3}{|c|}{ Factores desarrollados durante la visita } & 1 & 2 & 3 & 4 & 5 & 6 \\
\hline \multirow[t]{4}{*}{ Planificación } & \multirow[t]{2}{*}{$\begin{array}{l}\text { Planificación de } \\
\text { los contenidos }\end{array}$} & $\begin{array}{l}\text { Planificación previa } \\
\text { (hoja de planeamiento) }\end{array}$ & 480 & 488 & 680 & 678 & 388 & 375 \\
\hline & & $\begin{array}{l}\text { Aplicación de la planificación } \\
\text { durante la visita }\end{array}$ & 489 & 487 & 675 & 655 & 375 & 390 \\
\hline & \multirow[t]{2}{*}{ Secuenciación } & Manejo del tiempo & 455 & 421 & 612 & 608 & 325 & 325 \\
\hline & & $\begin{array}{l}\text { Desarrollo de los temas } \\
\text { (básicos y de profundización) }\end{array}$ & 457 & 477 & 687 & 674 & 366 & 356 \\
\hline \multirow[t]{3}{*}{ Metodología } & \multirow{3}{*}{$\begin{array}{l}\text { Estrategias } \\
\text { metodológicas }\end{array}$} & Materiales & 450 & 437 & 666 & 655 & 365 & 340 \\
\hline & & Recursos didácticos & 455 & 456 & 670 & 654 & 345 & 352 \\
\hline & & Abordaje de los temas & 488 & 491 & 675 & 663 & 356 & 363 \\
\hline \multirow[t]{3}{*}{ Determinación } & \multirow[t]{2}{*}{ Habilidades } & Desarrollo de habilidades "duras" & 425 & 445 & 645 & 654 & 365 & 360 \\
\hline & & Desarrollo de habilidades "blandas" & 480 & 475 & 657 & 625 & 370 & 375 \\
\hline & $\begin{array}{l}\text { Actitudes } \\
\text { y valores }\end{array}$ & $\begin{array}{l}\text { Fortalecimiento de valores } \\
\text { y actitudes ambientales }\end{array}$ & 495 & 488 & 690 & 689 & 395 & 390 \\
\hline Total & & & 4692 & 4665 & 6657 & 6555 & 3650 & 3625 \\
\hline
\end{tabular}

*En amarillo se muestran las variables mejor calificadas y en gris las variables con el menor puntaje.

La valoración de los docentes en la mayoría de los elementos evaluados alcanza el nivel máximo de satisfacción posible, en donde la única variable que se evalúa abajo del valor 4 implica una reducción en la cantidad de visitas al programa. Esto indica que los docentes reconocen que el programa Aula en el Bosque influye positivamente sobre la función docente en el abordaje del eje ambiental.

\section{DISCUSIÓN}

Comprensión de los temas ambientales por parte de los estudiantes: Los contenidos temáticos desarrollados dentro de la ejecución del Programa son mejor comprendidos por los estudiantes después de la visita al Aula en el Bosque. Lo anterior se justifica según lo expone Monroe (2010) debido a que un comportamiento ambiental responsable es producto de múltiples factores, que pueden ser tanto externos como intrínsecos a la persona y que a su vez son influenciados por otras variables; una de estas variables que cuenta con mucho peso es que el individuo se encuentre expuesto a un proceso de educación ambiental.
Este cambio cultural necesario -como se ha mencionado anteriormente- tiene su fundamento en la teoría sociocultural de Vygotsky. Henao, Ramírez y Ramírez (2007) mencionan que la educación como ente transformador de la cultura permite que los estudiantes desarrollen procesos psicológicos superiores, lo cuales crean cambios culturales en los que la naturaleza interacciona con el estudiante para este proceso. El Programa Aula en el Bosque facilita la interacción de los estudiantes con su entorno y con el medio natural, en interacción con sus compañeros e incluso con sus padres como observadores ocasionales, lo cual refuerza la adquisición de conceptos y comportamientos ambientales.

Castro y Balzaretti (2000) definen a la educación ambiental, como un instrumento privilegiado que instituye una nueva ética, que puede ser abordada por la pedagogía desde los tres ámbitos de la educación: formal, no formal e informal. Sin embargo, en Costa Rica, un problema particular es la falta de estrategias nacionales coordinadas entre programas formales e informales, y entre áreas de conservación, que lleven a un óptimo aprovechamiento de los recursos y una adecuada distribución de la información (Blum, 2008). 


\section{CUADRO 4}

Promedio de las respuestas de las encuestas aplicadas a los docentes durante las visitas de campo del programa "Aula en el Bosque" en el primer semestre del 2017.

\begin{tabular}{|c|c|c|c|c|c|}
\hline & & $\begin{array}{l}\text { Primer } \\
\text { grado }\end{array}$ & $\begin{array}{l}\text { Segundo } \\
\text { grado }\end{array}$ & $\begin{array}{l}\text { Tercer } \\
\text { grado }\end{array}$ & Promedio \\
\hline \multicolumn{6}{|c|}{ Estrategias y técnicas } \\
\hline 1 & Las técnicas utilizadas crearon interés & 5 & 5 & 4,5 & 4,83 \\
\hline 2 & El uso de materiales de apoyo fue adecuado & 5 & 5 & 5 & 5 \\
\hline 3 & El material usado fue acorde a la edad de los estudiantes & 5 & 5 & 5 & 5 \\
\hline 4 & Las técnicas utilizadas fueron innovadoras & 4 & 5 & 5 & 4,67 \\
\hline 5 & El desarrollo de las dinámicas fue claro y conciso & 5 & 5 & 4,5 & 4,83 \\
\hline \multicolumn{6}{|c|}{ Diseño de la clase en las aulas ambientales } \\
\hline 6 & Las aulas contaban con espacio necesario & 5 & 5 & 5 & 5 \\
\hline 7 & Las instrucciones para el uso del aula fueron claras & 5 & 5 & 4,5 & 4,83 \\
\hline 8 & El mobiliario presente es apto para los visitantes & 5 & 5 & 5 & 5 \\
\hline 9 & Las actividades iniciaron a tiempo & 4,5 & 5 & 5 & 4,83 \\
\hline \multicolumn{6}{|c|}{ Diseño del recorrido } \\
\hline 10 & Los senderos y sitios de trabajo permiten el desarrollo de las actividades & 5 & 5 & 4 & 4,67 \\
\hline 11 & Los temas son claros y oportunos & 5 & 5 & 4,5 & 4,83 \\
\hline 12 & La cantidad de visitantes en el sendero es adecuada & 5 & 5 & 4 & 4,67 \\
\hline 13 & La diversidad de flora y fauna presentes facilita el desarrollo de los objetivos & 4,5 & 4,5 & 5 & 4,67 \\
\hline 14 & El(la) educador(a) dirige de forma clara al grupo & 5 & 5 & 4,5 & 4,83 \\
\hline 15 & El recorrido es adecuado para los estudiantes & 4,5 & 5 & 5 & 4,83 \\
\hline \multicolumn{6}{|c|}{ Satisfacción del programa } \\
\hline 16 & Se logra cumplir con los objetivos & 5 & 5 & 5 & 5 \\
\hline 17 & Los estudiantes muestran interés en volver al programa & 5 & 5 & 5 & 5 \\
\hline 18 & La cantidad de visitas al año es adecuada & 5 & 5 & 5 & 5 \\
\hline 19 & La cantidad de visitas debería ser menor & 4 & 3 & 3,5 & 3,50 \\
\hline 20 & La cantidad de visitas debería ser mayor & 4 & 5 & 3,5 & 4,12 \\
\hline 21 & $\begin{array}{l}\text { El programa permite a los estudiantes integrar el conocimiento } \\
\text { de mejor manera comparada al aula de clase convencional }\end{array}$ & 5 & 5 & 4,5 & 4,83 \\
\hline \multicolumn{2}{|c|}{ Promedio } & 4,79 & 4,88 & 4,62 & 4,76 \\
\hline
\end{tabular}

Es por esto que resulta de gran importancia el planteamiento, ejecución y evaluación de un programa de educación ambiental como Aula en el Bosque. Lo anterior debido a que esta iniciativa permite amalgamar al gobierno local en representación municipal, el gobierno central por medio del MEP, la ciudadanía por parte de los estudiantes y cuerpo docente, todos estos actores inmersos con los recursos naturales y su importancia en nuestra permanencia planetaria.

Ejecución del programa In situ: Las evaluaciones de campo demuestran un impacto positivo en el desarrollo de los temas abordados, pero especialmente en la promoción de valores y actitudes ambientales. Y es que según Kollmuss y Agyeman (2002), las experiencias directas tienen una influencia más fuerte en el comportamiento de las personas que las experiencias indirectas, sobre esta línea se destaca la participación de los niños en el programa, al permitírseles vivenciar su aprendizaje en un entorno natural con ejemplos visuales tangibles que mejoren su aprehensión del conocimiento.

El complementar las lecciones magistrales con las visitas al Nacimiento les permite a los estudiantes desarrollar una mejor actitud ambiental. Esto debido a que durante el trabajo de campo el estudiante deja de ser un receptor pasivo de la información y se involucra activamente en su propio proceso de aprendizaje, mediante actividades lúdicas, tales como observaciones, experimentos, juegos y talleres (Vosniadou, 2001; Hannaford, 2008).

Adicionalmente, otro elemento fundamental de la teoría de Vygotsky aplicado al desarrollo de los programas de educación ambiental es el "análisis de los fenómenos 
desde su origen o génesis y no como un producto terminado" (Martínez, 1999, p.17). Lo anterior es fundamental en el modelo de aprendizaje constructivista, ya que los diferentes elementos se estudian y analizan en su origen, en su medio natural, lo que facilita su comprensión.

Pese a que el enfoque de este trabajo analiza de forma positivista el programa Aula en el Bosque se ha definido como un programa constructivista en sui desarrollo. Los resultados demuestran que la adquisición de valores y actitudes ambientales posee un gran impacto en desarrollo de las actividades.

Percepción de los docentes acerca del programa Aula en el bosque: Múltiples investigaciones apuntan que si estos programas educativos son dirigidos desde una edad temprana favorecen el incremento de actitudes positivas y por lo tanto, en su conducta hacia el medio (de Castro Cuéllar, Cruz Burguete \& Ruiz-Montoya, 2009). El análisis de resultados apoya este precepto al haber mostrado una mejora en las evaluaciones del posttest por sobre los resultados obtenidos en el pre-test, inclusive siendo éstos conceptos evaluados en individuos del primer ciclo de educación general básica.

La valoración de los docentes en la mayoría de los elementos evaluados alcanza el nivel máximo de satisfacción posible, un elemento de gran valor para la permanencia de la réplica en el cantón y su difusión a otras localidades, al haberse comprobado que funciona como una herramienta que colabora en complementar los objetivos curriculares solicitados por el MEP a los docentes. Es esencial recalcar la labor previa realizada en los salones de clase que facilitan el cumplimiento de los objetivos de Aula en el Bosque, al fortalecer la ejecución aprovechando la experiencia y el conocimiento de los docentes en pedagogía para lograr recorridos y dinámicas mejor ajustados a las audiencias meta (Zimmermann, 2005)

En general, todos los elementos indican que el programa impacta sobre el aprendizaje de los conceptos ambientales de los estudiantes y que estos conceptos parecen ser mejor aprendidos y retenidos por los estudiantes que son expuestos al programa. Lo anterior justifica la inversión municipal en términos del mejoramiento de la educación local, en cumplimiento de los fines del Gobierno Local en promover el bienestar colectivo de sus munícipes.

Por otro lado, el alcance mostrado en la promoción de actitudes y valores ambientales posee un alto valor educativo a largo plazo. El alcance temporal de este trabajo limita la posibilidad de determinar el potencial de este programa en la formación de aprendizaje significativo en los estudiantes, no obstante, evidencia una fuerte promoción y aplicación de elementos que permiten suponer que una exposición prolongada de estudiantes a este programa tendría un impacto en aprendizaje significativo.

La evaluación del Programa Aula en el Bosque demostró que su ejecución, cumple con los principales objetivos propuestos, por lo que se respalda la inversión municipal. A la vez que se promueve un modelo educativo ambiental en el cantón que contribuye con la formación de ciudadanos sensibilizados e informados de la realidad ambiental local desde edades muy tempranas.

\section{AGRADECIMIENTOS}

Agradecemos A la Municipalidad de Belén, por permitirnos evaluar su Programa de Educación Ambiental.

Agradecemos a los directores y directoras de los centros educativos estudiados por permitir el acceso a sus estudiantes y la aplicación de los instrumentos utilizados en esta investigación y a los miembros del cuerpo administrativo y docente que facilitan el cumplimiento del Programa.

\section{REFERENCIAS}

Ávila, M., Calatayud, M. A., Cantón, I., Castillo, S., \& Zaitegui, N. (2010). La evaluación como proceso sistemático para la mejora educativa. España: Ministerio de Educación Cultura y Deporte.

Blum, N. (2008). Environmental education in Costa Rica: Building a framework for sustainable development. International Journal of Educational Development, 28(3), 348-358. doi:10.1016/j.ijedudev.2007.05.008

Castro, E., \& Balzaretti, K. (2000). La educación ambiental no formal posibilidades y alcances. Revista Educar, 13, 53-60.

Colón Ortiz, A. (2011). La Educación Ambiental: una herramienta para la protección y conservación del entorno. Revista $360^{\circ}, 6,1-5$.

de Castro Cuéllar, A., Cruz Burguete, J., \& Ruiz-Montoya, L. (2009). Educar con ética y valores ambientales para conservar la naturaleza. Convergencia, 16(50), 353-382.

Espejel, E., Castillo, I. y Martínez de la Fuente, H. (2011). Modelo de educación ambiental para el nivel medio superior, en la región Puebla-Tlaxcala, México: un enfoque por competencias. Revista Iberoamericana de Educación, 55(4), $1-13$.

Guier, E., M. Rodríguez y M. E. Zúñiga. (2000). Didáctica ambiental. San José, Costa Rica: EUNED.

Hannaford, C. (2008). Aprender moviendo el cuerpo. México DF, México: Pax. 
Henao, G., Ramírez, C., \& Ramírez, L. (2007). Las prácticas educativas familiares como facilitadoras del proceso del desarrollo del niño y la niña. AGO.USB Medellín-Colombia, $7(2), 199-385$.

Hernández, M. (2013). Evaluación del programa de educación ambiental formal "Aula al aire libre" Reserva Los Coyotes. Revista Electrónica Actualidades Investigativas en Educación, 13(2), 1-32.

Kollmuss, A., \& Agyeman, J. (2002). Mind the Gap: Why do people act environmentally and what are the barriers to pro environmental behavior. Environmental Education Research, 8(3), 239-260.

Leopold. L., Clarck, F., Hanshaw, B., \& Balsley, J. (1971). A procedure for evaluating environmental impact. Washington DC: Geological Survey Circular 645.

Martínez, M. (1999). El enfoque socio cultural en el estudio del desarrollo y de la educación. Revista Electrónica de Investigación Educativa, 1(1), 17-36. Recuperado de: http://www.redalyc.org/html/155/15501102/.
Monroe, M. C. (2010). Challenges for environmental education evaluation. Evaluation and Program Planning, 33(2), 194196. doi: 10.1016/j.evalprogplan.2009.07.012

Salazar, E. (2015). Inventario de Gases efecto invernadero de las escuelas primarias de Belén, Heredia, Costa Rica. UNED Research Journal, 7(2), 193-200.

Thomson, G., Hoffman, J., \& Staniforth, S. (2010). Measuring the Success of Environmental Education Programs. Ottawa: Canadian Parks and Wilderness Society and Sierra Club of Canada.

Tintoré, J. (2006). Investigación, medio ambiente y sostenibilidad: el Nuevo papel de la ciencia y la contribución del IMEDEA. Ambienta, 53, 59-63.

UNESCO. (2004). Esquema Internacional de Implementación para la Década de Educación para el Desarrollo Sostenible. UNESCO.

Vosniadou, S. (2001). How children learn. Brussels, Belgium: International Academy of Education.

Zimmermann, M. (2005). Ecopedagogía: el planeta en emergencia. Bogotá, Colombia: Ecoe. 